\title{
Determination of Lycopene Content in Red Vegetable Grown in Sri Lanka
}

\author{
KMAD Jayamaha ${ }^{1}$, UMA Kumara ${ }^{2 *}$ and CR Gunawardhana ${ }^{3}$ \\ ${ }^{1}$ University College of Anuradhapura, University of Vocational Technology, Sri Lanka \\ ${ }^{2}$ Department of Agricultural Technology, Faculty of Technology, University of Colombo, Sri Lanka \\ ${ }^{3}$ National Institute of Postharvest Management, Anuradhapura, Sri Lanka \\ *Corresponding Author: UMA Kumara, Department of Agricultural Technology, Faculty of Technology, University of Colombo, Sri Lanka.
}

Received: October 29, 2019; Published: November 14, 2019

DOI: 10.31080/ASAG.2019.03.0722

\begin{abstract}
Lycopene, an optimistic red carotenoid colorant has fascinated significant attention between the well-being expert due to its high antioxidant properties. The Lycopene content of selected Tomato, Beetroot, Red Cabbage, Amaranthus, and Red Chili commonly consumed in Sri Lanka were determined using theoretical and experimental methods. The lycopene content ranged from 13.65 to 43.60\% in Tomato, 1.43-2.58\% in Amaranths, 0.33- 0.5\% in Beetroot, 20.91-48.91\% in Red Chili and 1.34-1.54\% in red cabbage. This study has shown that red chilli is very rich in lycopene followed by fresh tomato, ameranthus, red cabbage, and beetroot. These vegetables have to be habitually included in the intake for sufficient supply of lycopene.
\end{abstract}

Keywords: Lycopene Content; Sri Lanka; Tomato; Red Cabbage; Red Chili; Beetroot; Amaranths

\section{Introduction}

Novel life styles have focused consumers left from healthy dietary habits. For example, a matter of fact, their growing concern about their health has encouraged the need for food produces which provide to the prevention of illness. Vegetables are a good source of natural anti-oxidants, containing several different antioxidants components which deliver protection against harmfulfree revolutionaries and have related with lower rate and humanity rates of cancer and heart diseases in addition to a number of other health benefits. Between these compounds, the carotenoids create a vital group in human diets and display, in addition to their vitamin activity, several other biological activities including antioxidant capacity, blue light filtering, variety of immune function and guideline of cell differentiation and proliferation. Some $70-90 \%$ of the carotenoids content of the human diet provided by vegetables. The most capable carotenoid antioxidant is lycopene which was first isolated in 1910. It is mainly produced by higher plants; in which it keeps cells alongside photo-oxidation. Lycopene is a carotenoid colorant, originate in tomatoes and other red fruits, and vegetables. Its name is resulting from the tomato's species taxonomy, Solanum lycopersicum.

Lycopene, related to further carotenoids, is a natural fat-soluble colorant (red, in the case of lycopene) which is produced by some floras and micro-organisms but not by faunae, where it works as an addition light-gathering colorant and to defend these beings against the poisonous effects of oxygen and light.

Lycopene is also a key carotenoid in human blood initiate to have moderately, stouter antioxidant properties than key plasma carotenoids. Lycopene was informed to be a greatly operative antioxidant remaining to its capability to performance as a free essential scavenger and has the highest singlet oxygen quenching rate of all the carotenoids tested from genetic systems. Report designates that human body is incapable to produce carotenoids from endogenous formed compounds and entirely depends on dietary bases of carotenoids. About medical exploration studies have informed fruits and vegetables, specially tomato as the good food sources of 
Lycopene. Also founded that great consumption of tomato foodstuffs prevented the danger of prostate cancer which is probable owing to the act of the lycopene content. It would be beneficial to identify the total lycopene content of tomato, fruits and vegetable in each vicinity to create how the evidence may convert into nutritional consumption to fulfil the necessity for lycopene and carotenoids by separable.

This revision resolute the lycopene content of tomato, red cabbage, red chili, amaranths and beetroot normally expended in Sri Lanka.

\section{Materials and Methods}

- Sample Collection and preparation: Selected red vegetables such as tomato, red chili, red cabbage, beetroot and amaranths were obtained from the different fields in Sri Lanka. In the case of vegetables, special attention was engaged to choice the best matured samples. About 500g$1 \mathrm{~kg}$ of respectively sample of vegetables were gained from each fields. The eatable portion of vegetable samples from the dissimilar fields were washed and cleaned with water and finally cleaned with deionized water to eradicate infection. Each sample was cut into slighter pieces, homogenized to gain a uniform single complex sample of the same type of vegetables.

- Chemical Analysis: The chemical used for the study of the food samples include: Butylated hydroxytoluene (BHT), acetone, hexane, ethanol, deionized water and lycopene standard.

- Preparation of Lycopene Standard: Lycopene standard solution in hexane $(5 \mathrm{mg} / \mathrm{ml})$ was arranged and covered in a piece of paper foil and kept in the shady at 40C. Functioning combinations of several related meditations were prepared by suitable mixture and dilution with hexane. The conjugated-paired bond system of carotenoids in common could produce the leading problems with their running (they are uneven to light, oxygen, heat, acid and alkaline conditions). Therefore, specific care was rewarded on the sample/standard preparation, during operation and storing to inhibit this intrusion. Numerous solutions of lycopene in $n$-hexane at diverse concentration were made ranging from $0.005-50 \mathrm{mg} / \mathrm{l}$ and absorbance was measured at $503 \mathrm{~nm}$, after proper standardization of the apparatus with hexane.
- Extraction of Lycopene in the Vegetable Samples: Later the standardization curve was acquired, the removal of lycopene from the food samples was done according to Fish., et al. (2002). Samples were first sliced and make uniform in a laboratory homogenizer. Around $0.6 \mathrm{~g}$ of each food sample was balanced and $5 \mathrm{ml}$ of $0.05 \%(\mathrm{w} / \mathrm{v}$ ) BHT in acetone, $5 \mathrm{ml}$ of ethanol and $10 \mathrm{ml}$ of hexane were added. The receiver was presented into ice and stimulated on a magnetic stirring plate for $15 \mathrm{~min}$. Afterward shaking, $3 \mathrm{ml}$ of deionized water was added to each vial and the samples were shaken for 5 minutes on ice. Samples were then kept at room temperature for 5 minutes to let for the phase separation.

- Lycopene content of foods and tomato fruits was measured spectophotometrically at $503 \mathrm{~nm}$ after an extraction with hexane. Concentration of lycopene was derived using the molar extinction coefficient of $17.2 \times 104$ in the theoretical method of and also by applying the following equation in the experimental method described by Ravelo-Perez., et al. (2008): Lycopene content $(\mathrm{mg} / \mathrm{kg})=(\mathrm{A} 503-0.0007) \times 30.3 / \mathrm{g}$ tissue .

The Lycopene content of the selected food samples determined in this study was calculated using both the theoretical and experimental methods.

\section{Results}

The mean values of lycopene contents of the food samples using both the theoretical and the experimental methods are presented in below figure 1 .

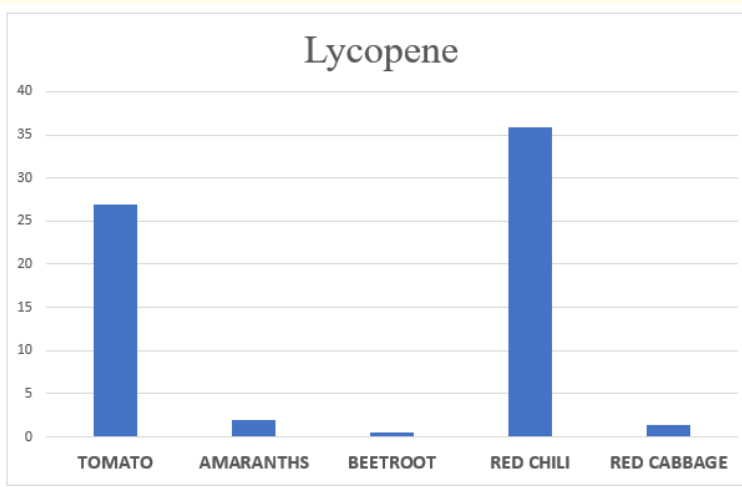

Figure 1: Lycopene content of tomato, amaranths, beetroot, red chili, red cabbage in Sri Lanka. 
Lycopene varied widely among the various fresh fruits ranging from 13.65 to $43.60 \%$ in tomato, $1.43-2.58 \%$ in amaranths, 0.33 - $0.5 \%$ in beetroot, $20.91-48.91 \%$ in red chilli and $1.34-1.54 \%$ in red cabbage. The lycopene content in red chilli was significantly higher than the other selected fresh vegetables. Amongst selected vegetables beetroot had the lowest lycopene content [1-6].

\section{Discussion and Conclusion}

Lycopene is recognized to be one of the greatest effective antioxidant between nutritional carotenoids. Significant the lycopene content of usually expended diets is beneficial in scheduling dietary plans to fulfill the reference day-to-day consumption for antioxidant and also as beneficial keys of possible health profits, of specific plant-based foods. The valuable things of vegetables are imagined.

The end result obtainable in the study has exposed that lycopene content wide-ranging among vegetables representing the essential of diverse portions of these foods. Between the food samples examined, red chili had the maximum content of lycopene. In the second place lycopene content most had in tomatoes. Other selected vegetables had lowest content of lycopene, commonly consumed in the Sri Lanka.

\section{Bibliography}

1. Lilwani S and Nair V. "Extraction and Isolation of Lycopene Form Various Natural Sources". IOSR Journal of Biotechnology and Biochemistry (IOSR-JBB) 5 (2015): 49-51.

2. Kunnumakkara AB. "Anticancer Properties of Fruits and Vegetables: A Scientific Review”. World Scientific (2014).

3. Barber NJ and Barber J. "Lycopene and prostate cancer". Prostate Cancer and Prostatic Diseases 5 (2002): 6.

4. Hashemi M., et al. "Bioinformatic Analysis for Anticancer Effects of Flovonoids in Vegetables and Fruits". International Conference on Biological, Civil and Environmental Engineering (2014).
5. Fadupin GT., et al. "Lycopene Content of Selected Tomato Based Products, Fruits and Vegetables Consumed In South Western Nigeria". African Journal of Biomedical Research 15 (2012): 187-191.

6. Ordoñez-Santos LE. and Ledezma-Realpe DP. "Lycopene concentration and physico-chemical properties of tropical fruits". Food and Nutrition Sciences 4 (2013): 758.

\section{Volume 3 Issue 12 December 2019}

(C) All rights are reserved by UMA Kumara., et al. 